$12-2002$

\title{
The Impact of Density: The Importance of Nonlinearity and Selection on Flight and Fight Responses
}

Wendy C. Regoeczi

Cleveland State University, w.regoeczi@csuohio.edu

Follow this and additional works at: https://engagedscholarship.csuohio.edu/clsoc_crim_facpub

Part of the Place and Environment Commons, Quantitative, Qualitative, Comparative, and Historical Methodologies Commons, and the Social Psychology and Interaction Commons

How does access to this work benefit you? Let us know!

Publisher's Statement

(c) 2002 Oxford University Press

\section{Original Citation}

Regoeczi, W. C. (2002). The Impact of Density: The Importance of Nonlinearity and Selection on Flight and Fight Responses. Social Forces, 81(2), 505-530.

\section{Repository Citation}

Regoeczi, Wendy C., "The Impact of Density: The Importance of Nonlinearity and Selection on Flight and Fight Responses" (2002). Sociology \& Criminology Faculty Publications. 83.

https://engagedscholarship.csuohio.edu/clsoc_crim_facpub/83

This Article is brought to you for free and open access by the Sociology \& Criminology Department at EngagedScholarship@CSU. It has been accepted for inclusion in Sociology \& Criminology Faculty Publications by an authorized administrator of EngagedScholarship@CSU. For more information, please contact library.es@csuohio.edu. 


\title{
THE IMPACT OF DENSITY: THE IMPORTANCE OF NONLINEARITY AND SELECTION ON FLIGHT AND FIGHT RESPONSES
}

\author{
Wendy C. Regoeczi, Cleveland State University
}

This article was originally published in:

Regoeczi, Wendy C. (2002). The Impact of Density: The Importance of Nonlinearity and Selection on Flight and Fight Responses. Social Forces, 81(2), 505-530.

Post-print standardized by MSL Academic Endeavors, the imprint of the Michael Schwartz Library at Cleveland State University, 2013

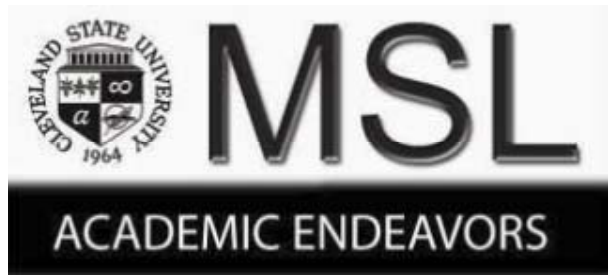




\title{
The Impact of Density: The Importance of Nonlinearity and Selection on Flight and Fight Responses ${ }^{\star}$
}

\author{
Wendy C. RegoeCZI, Cleveland State University
}

\begin{abstract}
Unlike commonsense notions and the findings from animal research, the literature concerning the effects of density on human social behavior is paralyzed by contradictory findings. This article examines empirically two fundamental issues which could account for this and which are central to the density-crowding debate: (1) whether observed crowding effects are the result of causation or selection and (2) whether individuals are negatively affected by both low and high levels of density. Data from the Toronto Mental Health and Stress study are analyzed using structural equation modeling to investigate these questions. The results support the notion that the effects of density on aggressive and withdrawn behavior are nonlinear in nature. The findings further reveal a self-selection of respondents into particular forms of housing. The implications of these findings for future research on crowding are discussed.
\end{abstract}

For many years urban sociologists, social psychologists, and criminologists have argued that there is a direct relationship between the size of a city and the level of social pathology (Gillis \& Hagan 1983). Density is often thought to have a particularly detrimental impact on the health and behavior of urban residents. The precise nature of this relationship, however, appears to have eluded researchers. This article employs structural equation modeling to address several issues concerning the specification of density effects. In particular, the current study is unique in its empirical evaluation of the selection/causation issue regarding the relationship of density to various behavioral outcomes. It

${ }^{*}$ I gratefully acknowledge the statistical advice of Kenneth A. Bollen, and would like to thank A. $R$. Gillis, Blair Wheaton, Robert Silverman, Vincent Sacco, William Magee and the anonymous reviewers for their helpful comments. Direct correspondence to Wendy C. Regoeczi, Department of Sociology, Cleveland State University, 1860 East 22nd Street, Cleveland OH, 44114-4435.

E-mail:w.regoeczi@csuohio.edu. 
also investigates the rarely acknowledged question of whether the impact of density is nonlinear in nature. The findings speak to some fundamental issues that are central to the density-crowding debate.

The works of ethologists such as Lorenz (1967) and Morris (1967, 1971) likely contributed to the popular concern surrounding density effects (Gillis 1974). Early evidence of the pathological effects of crowding came from animal studies (e.g., Calhoun 1962; Christian 1961, 1963, 1970; Christian, Flyger, \& Davis 1960; Davis 1971; Keeley 1962; Myers et al. 1971; Thiessen \& Rodgers 1961). Research on crowded animal populations reported increased levels of aggressive behavior (e.g., Flickinger 1966; Greenberg 1972; Gregor et al. 1972; Willis 1966), heightened mortality (Allee et al. 1949; Christian et al. 1960; Petrusewicz 1957; Thiessen \& Rodgers 1961), and reduced fertility and natality (Calhoun 1962; Clulow \& Clarke 1968; Davis 1964; Hoffman 1958; Keeley 1962; Lockley 1961; Terman 1965) under high-density conditions. Out of this literature emerged the notion of "fight versus flight" responses among animals in dealing with issues of space and territoriality (see McBride 1971).

Two major types of theoretical arguments have developed concerning the possible effects of density on human behavior which mirror these fight versus flight responses in animals. One perspective views behavioral responses to density as one of withdrawal from social life (e.g., Milgram 1970; Simmel [1905] 1957; Wirth 1938). Situations requiring interaction with large numbers of people may lead to social overload and threaten regulation of interaction (Baum \& Koman 1976). In response, individuals may try to withdraw and separate themselves from others as a means of diminishing the chances of coming into contact with others or to regain control over the social situation. Thus, withdrawal functions as both a method of protection and escape (Booth 1976). Adaptation to crowded environments may therefore occur through withdrawal, and individuals may "tune out" social stimulation as a means of reducing social overload (Baum \& Paulus 1991; Evans et al. 2000).

An alternative perspective on the consequences of crowding argues that frustration generated by high levels of population density will stimulate aggression in individuals. Animal studies form the basis of many of the arguments claiming a positive relationship between population density and aggressive behavior (Calhoun 1962; Lorenz 1967; van den Berghe 1974). Ethologists have long known that in many species, population pressure or population density has a direct relationship to aggression (van den Berghe 1974). Population pressure provokes resource competition, which heightens aggressive behavior. Population increases are permitted to occur until the animals receive signals that the supply of survival essentials (e.g., food, territory) can no longer meet the needs of the population (Booth 1976). The nature of these cues is uncertain, but the reaction is a striking escalation of aggressive incidents within the population. The aggressive drive is also at the basis of distance-maintaining behavior among animals (Eibl- Eibesfeldt 1970). 
Among humans, deviant social behavior is often witnessed in overly crowded areas, the major producers of which are build-ups of tension and frustration (Beasley \& Antunes 1974). High population density is one of a group of factors present in urban life which may contribute to criminality through the generation of anonymity, frustration, conflicting norms, anomie, and the like (Wolfgang 1970). Crowding creates a more impersonal atmosphere, increases opportunities for association with deviant role models, and provides greater numbers of targets for aggression (Booth, Welch \& Johnson 1976). Aggressive reactions to crowding may also occur at the household and neighborhood level. Behavior may be restricted or limited in crowded environments, leading to difficulties in exercising one's freedom of choice (Baron \& Rodin 1978; Baum \& Valins 1979; Lawrence 1974). The close proximity of others may cause difficulties with the most routinized behaviors (Baum \& Valins 1979). Aggression may encourage others to relocate elsewhere, relinquishing some of their space to the aggressive individual, in turn alleviating a number of the constraints connected with crowding (Baum \& Paulus 1991). Frustration may also arise in response to decreasing environmental resources that can result from increases in population density (Altman 1975; Baldassare 1979; Michelson \& Garland 1974; Verbrugge \& Taylor 1980).

\section{Respecifying the Effects of Density}

Though the view that living in a crowded environment is unhealthy is well supported by research on animal populations, researchers who have set out to demonstrate empirically the harmful effects of crowding among humans have had a difficult time doing so. Some studies find that high density leads to withdrawal (e.g., Aiello, Thompson \& Baum 1984; Baum \& Paulus 1991; Evans et al. 2000; Gove \& Hughes 1983; Hutt \& Vaizey 1966; Jain 1987; Lepore, Evans \& Schneider 1991; Loo 1972; Sundstrom 1975; 1978; Valins \& Baum 1973), or aggression (e.g., Aiello, Nicosia \& Thompson 1979; Gove, Hughes \& Galle 1979; Loo 1978; 1979; Mackintosh, West, \& Saegert 1975), while other studies find no effect of density on human social behavior (e.g., Booth \& Cowell 1976; Booth \& Edwards 1976; Stokols et al. 1973; Worchel \& Teddlie 1976).

Several decades later, there is little consensus as to whether - and how high urban density is related to various behavioral outcomes. This article argues that the inconsistent results that plague the density literature are due to a misspecification of how density effects operate. In particular, there are several issues with respect to how density effects are specified that, left unaddressed, lead to serious misrepresentations of the relationship of density to pathology. These issues pertain to self-selection and nonlinear effects of density on social behavior. 


\section{Self-Selection}

Self-selection arguments are concerned with the issue of reverse causation. Whether the relationship between density and social behavior results from a tendency of particular types of individuals to select themselves into certain housing situations is an issue that plagues much of the findings in the crowding literature. For example, individuals who are difficult to get along with may be more likely to move into smaller apartments where they live by themselves (Galle, Gove, \& McPherson 1972). Unfortunately, this tends to be difficult to address in the sense that individuals' exposure to varying levels of density under nonexperimental conditions does not occur randomly. In survey research, initial measurements of density and health/behavior often occur simultaneously, making it hard to establish which is the cause and which is the effect. Panel surveys provide a distinct advantage in this regard, because they permit an assessment of changes over time in both density and its possible outcomes. Nevertheless, even these types of surveys tend to commence long after exposure to particular levels of density has begun, therefore precluding the possibility of obtaining measures on the dependent variables at the point of initial exposure to particular levels of density. Still, they represent a significant improvement over measures collected at only one point in time.

A few studies have addressed the issue of self-selection directly by testing for the possibility of reverse causation in their analyses. For example, Lepore, Evans and Palsane (1991) controlled for prior psychological symptoms in examining the effect of residential density on psychological distress and found little evidence of self-selection occurring in their sample of American college students. In other analyses of data collected from college students, Lepore, Evans and Schneider (1991) ruled out the possibility of any systematic selection of individuals into crowded apartments on the basis of levels of psychological distress after finding no significant associations between household crowding and initial levels of psychological distress. Other researchers have managed to develop and test hypotheses to address issues of self-selection in cross-sectional data. Hughes and Gove (1981), for example, argue that examining various characteristics of persons living alone may provide some evidence as to whether selection processes play a major factor in why these individuals reside by themselves. However, studies which explicitly test for the possibility that the effects of density are the result of selection rather than causation in their samples are by far the minority in the existing literature and are typically limited to research on college students. However, the failure to rule out selfselection as an explanation for the relationship between density and various social and behavioral outcomes brings into doubt much of what we know (or think we know) about how density affects individuals. 


\section{Nonlinear EfFects of Density}

There is a need to explore the nature of crowding effects in terms of possible nonlinear relationships with behavioral outcomes. A group of researchers have theorized that density may have some positive outcomes (e.g., Freedman 1975; Hawley 1972; Jacobs 1961; Keane 1989; Michelson 1976; Michelson \& Garland 1974; Proshansky, Ittelson \& Rivlin 1970; van Vliet 1985; Verbrugge \& Taylor 1980). These positive effects may come in the way of increased social resources, informal ties, informal contacts and greater assistance among people, all of which may lead to increased social integration. However, if density does in fact have some benefits, these may be limited to moderate levels of density, thereby suggesting the possibility of a nonlinear relationship. Consequently, it is important to investigate whether more deleterious effects ensue from the lowest levels of crowding compared to medium levels. The possibility of an "ideal range" of density has received consideration elsewhere (Altman 1975; Baum \& Paulus 1991; Carnahan, Gove, \& Galle 1974; Gabe \& Williams 1986; Galle \& Gove 1978; Gillis 1979). For example, various researchers have proposed the idea of an optimal level of social stimulation, with both underand over-stimulation being avoided (e.g., Altman 1975; Rapoport 1975). Various studies report findings which support the notion of nonlinearity in density effects for both animals (Allee 1938) and humans (Gabe \& Williams 1986; Gillis 1979).

Nonlinearity may be a key factor in explaining the inconsistent findings of past research. That is, the negative effects, no effects, and positive effects that have emerged in previous studies may actually reflect different parts of the curve. The difference between, say, 0.3 persons per room and 0.7 persons per room may not be the same as the difference between 1.5 and 1.9 persons per room. What is more likely to be the case is that there is a threshold effect and that only after a point does the density effect take off. Up until that point, the addition of extra people either has no negative effect or is in fact advantageous in terms of added social support benefitting people's social behavior. Determining whether there is such a threshold is one of the central focuses of this research.

\section{Methodology}

SAMPLE

This article examines data from the Toronto Mental Health and Stress Study (Turner \& Wheaton 1992) to assess the effects of interior and exterior density on behavioral outcomes. The design of the study involved a multi-stage cluster sampling strategy. Individuals were randomly selected from households from 
a representative sample of dwelling addresses drawn from within 2001986 Census Enumeration Areas (of a total of 3,088 Census Enumeration Areas that comprise the six borough target areas). The first wave, conducted in 1990-91, yielded 1,393 interviews (a response rate of $75.3 \%$ ). The second wave, conducted approximately one year later, reinterviewed 1,206 respondents (a response rate of $86.6 \%$ ). The longitudinal component of the study permits a testing of self-selection arguments.

The location of the study is especially valuable in light of the subject matter. Toronto may provide a unique opportunity to disentangle the effects of crowding and socioeconomic status. A common criticism of early correlational studies of the relationship between density and various forms of social pathology was their inability to distinguish between the effects of density per se and the effects of factors, such as poverty, that tend to coexist with high density (e.g., Factor \& Waldron 1973). However, Toronto is unusually structured in the sense that high-rise buildings are spread across neighborhoods of varying socioeconomic levels. Therefore, the presence of a crowding / socioeconomic status correlation is offset by the fact that some of the more crowded areas of the city are high socioeconomic neighborhoods. Further, more suburban areas, which are lower in density, are often not high in socioeconomic status.

\section{Measures}

\section{Household Density}

The survey contains data on both the number of persons in the household and the number of rooms in the household, and thus persons per room can be calculated by dividing the latter by the former. ${ }^{1}$ A squared version was also constructed in order to test for the possibility of nonlinear effects.

The study includes two outcome measures, both of which are treated as latent variables.

\section{Withdrawal}

A scale measuring withdrawn behavior was constructed on the basis of respondent self-ratings on the following statements: it is hard for me to feel close to other people; I keep other people at a distance too much; it is hard for me to experience a feeling of love for another person; it is hard for me to show affection to other people; it is hard for me to socialize with other people; it is hard for me to introduce myself to new people; it is hard for me to join in on groups. The items were scaled such that $0=$ not at all well; $2=$ moderately well; $4=$ extremely well. 
A measure of aggressive behavior was constructed on the basis of the following respondent ratings concerning the degree to which each statement describes them: I am too aggressive toward other people $(0=$ not at all well $-4=$ extremely well); I manipulate other people too much to get what I want $(0=$ not at all well $-4=$ extremely well); submissive/forceful ( $1=$ submissive -7 = forceful); not at all aggressive/aggressive $(1=$ not at all aggressive $7=$ aggressive); I like people to be afraid of me; I try to get into positions of authority $(1=$ very unlike me $-5=$ very like me).

The measures of both aggression and withdrawal are self-reporting in nature. They were designed to tap into a range of social responses to highdensity environments. For example, one can conceive of aggression as consisting of continuum, moving from aggressive attitudes and other nonverbal and nonphysical forms on one end to aggressive behavior on the other end, with verbal aggression falling somewhere in between. Aggression may function as a response to crowding by inducing others to relinquish space and resources to the aggressive individual. Aggression need not be limited to the physical realm to accomplish this goal. Individuals exhibiting aggressive attitudes and who are verbally aggressive may also be successful in gaining control over their surroundings. The measure of aggression used in the current study may best be conceptualized as a measure of aggressive tendencies.

\section{Control Variables}

Keeping in mind the nature of both the independent and dependent variables of interest here, the control variables selected were gender (females $=1$; males =0;), marital status (never married, previously married, and married as the reference category), ethnicity (black; southern European; eastern European; Euro-Mediterranean; and white as the reference category), and household income (measured using a 15-point scale ranging from under Can $\$ 5,000$ to Can $\$ 135,000$ and above). Descriptive statistics for these variables are available upon request.

\section{ANALYsIS}

Structural equation modeling was used to test self-selection and nonlinearity arguments concerning the effects of density. Separate models for withdrawal and aggression were developed and tested using a two-stage least squares estimator (2SLS) developed by Kenneth A. Bollen $(1995,1996)$, which has specific application to structural equation models containing nonlinear functions among latent variables or a mixture of latent and observed variables. The same models were then reanalyzed using LISREL (Jöreskog \& Sörbom 
1995). The major disadvantage of selecting a technique such as 2SLS concerns the estimator property of efficiency. While Bollen (1995) demonstrates the consistency of his 2SLS estimator, full information methods such as LISREL provide more efficient estimators than limited information methods (Johnston 1984). To address this issue, all of the models that were analyzed using 2SLS were analyzed a second time using LISREL in order to assess the extent to which the results of the former may have been affected by the inefficiency of the 2SLS estimator, thereby increasing confidence that any coefficients not found to be significant in the 2SLS analysis are not due to the inefficiency of the estimator.

Bollen's method consists of substituting observed variables for the latent variables in the original equation and then estimating the parameters using instrumental variable methods. In this way, the latent variable model is rewritten into an equation containing observed variables and a composite disturbance term. The first-stage regression involves regressing each variable in the equation derived from the path model on a group of instrumental variables that are correlated with the variables in the equation but are uncorrelated with the disturbance of that equation. The predicted variables from the first stage, which are uncorrelated with the disturbance term of the original equation as a result of the fact that they are linear combinations of the instrumental variables, replace the original variables from the model equation in the second-stage regression. The coefficient estimators from the second stage are consistent estimators of the corresponding coefficients in the original equation with latent variables. They also have a known asymptotic distribution, thus permitting the estimation of standard errors and the performance of significance tests.

\section{Results}

Figures 1 and 2 show the full system of equations for withdrawal and aggression respectively, which were estimated as a means of testing self-selection and nonlinearity arguments. Keeping with convention, ovals are used to represent latent variables and boxes to represent observed variables. Single-headed arrows represent direct effects. $X_{1}$ through $X_{7}$ and $Y_{1}$ through $Y_{7}$ represent indicators of withdrawal $\left(X_{1}, Y_{1}-X_{6}, Y_{6}\right.$ in the case of aggression) and correspond to the order in which these scale items are listed in the Measures section. $X_{8}$ and $Y_{8}$ ( $X_{7}$ and $Y_{7}$ in the case of the model for aggression) are measures of persons per room at time 1 and time 2 respectively. Although included in the analyses, the control variables were left out of the diagram for the sake of clarity.

There were two equations for each outcome that were of central interest. Equation 1 examines the effect of time 2 density and time 2 density $^{2}$ on time 2 withdrawal (aggression), controlling for time 1 withdrawal (aggression). This equation essentially tests whether current crowding has an impact on 
FIGURE 1: Structural Equation Model of the Relationship between Density and Withdrawal

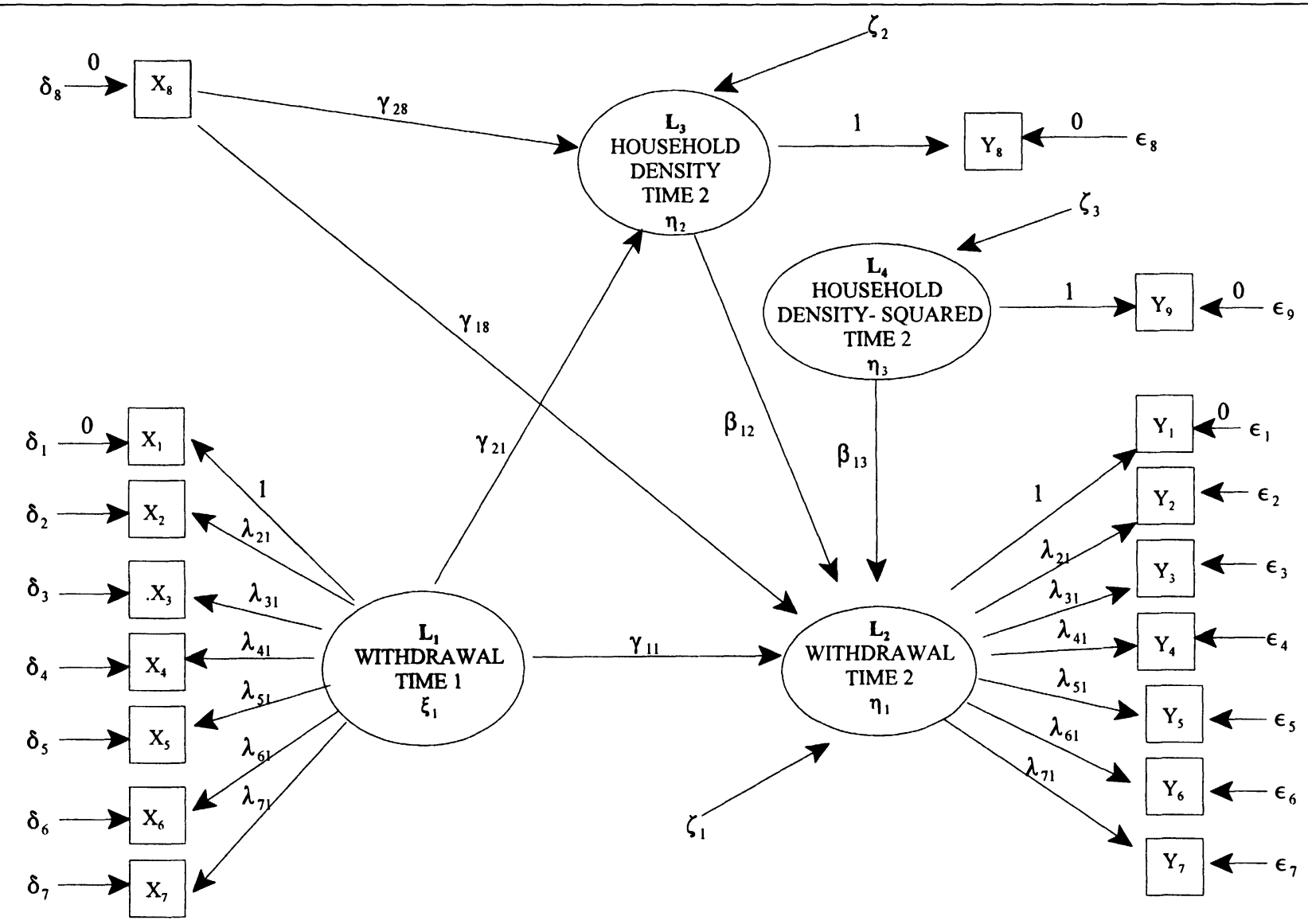


FIGURE 2: Structural Equation Model of the Relationship between Density and Aggression

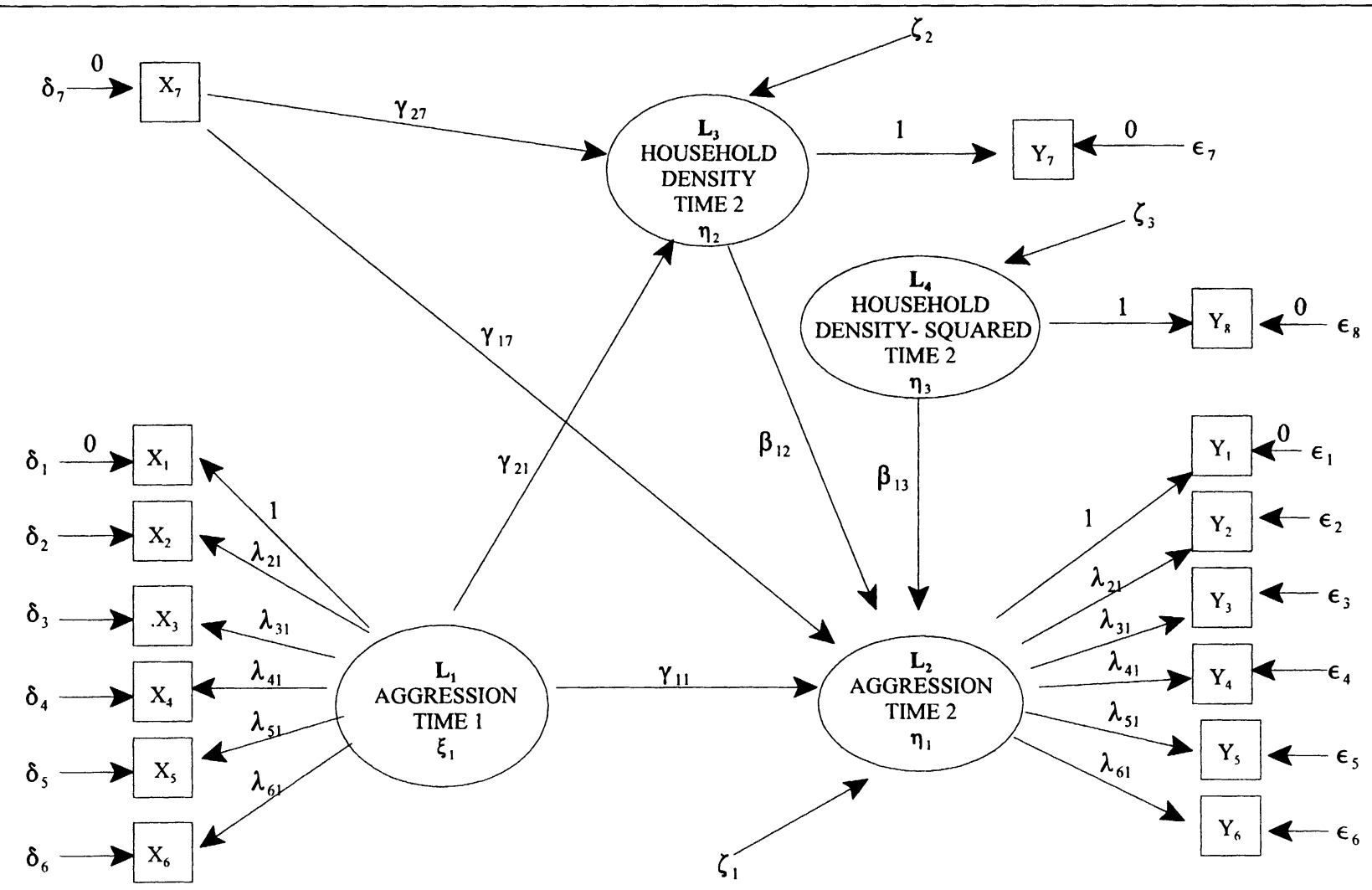




\section{TABLE 1: Structural Equation Model Testing for Self-Selection and Nonlinearity in the Relationship between Density and With- drawal}

\section{Factor Loadings for Latent Variables}

Withdrawal, Time 1

Factor
Variable $\quad$ Loading

$\mathrm{x}_{1} \quad .86$

$\mathrm{x}_{2} \quad .74$

$\mathrm{x}_{3} \quad .72$

$\mathrm{x}_{4} \quad .71$

$\mathrm{x}_{5} \quad .65$

$\mathrm{x}_{6} \quad .55$

$\mathrm{x}_{7} \quad .55$
Withdrawal, Time 2

Factor

Variable Loading

$\begin{array}{ll}\mathrm{y}_{1} & .79\end{array}$

$\mathrm{y}_{2} \quad .71$

$\mathrm{y}_{3} \quad .63$

$\mathrm{y}_{4} \quad .66$

$\mathrm{y}_{5} \quad .64$

$\mathrm{y}_{6} \quad .57$

$\mathrm{y}_{7} \quad .57$

Equation 1: The Effects of Time 2 Density and Density-Squared on Time 2 Withdrawal

$\begin{array}{lcc}\text { Variable } & \begin{array}{c}\text { Parameter } \\ \text { Estimate }\end{array} & \begin{array}{c}\text { Standard } \\ \text { Error }\end{array} \\ & & \\ \text { Persons per room }(\text { time 2) } & -7.902^{\star *} & 2.742 \\ \text { (Persons per room) }^{2}(\text { time 2) } & 3.347^{\star *} & 1.196 \\ \text { Withdrawal (time 1) } & .2921^{\star * * *} & .0859\end{array}$

Equation 2: The Effects of Time 1 Withdrawal on Time 2 Density

$\begin{array}{lcc}\text { Variable } & \begin{array}{c}\text { Parameter } \\ \text { Estimate }\end{array} & \begin{array}{c}\text { Standard } \\ \text { Error }\end{array} \\ & & \\ \text { Withdrawal (time 1) } & -.0130 \dagger & .0079 \\ \text { Persons per room (time 1) } & .7464^{* * * *} & .0299\end{array}$

$\dagger \mathrm{p}<.10 \quad{ }^{*} \mathrm{p}<.05 \quad{ }^{* *} \mathrm{p}<.01 \quad{ }^{* * *} \mathrm{p}<.001 \quad{ }^{* * * *} \mathrm{p}<.0001$

withdrawal (aggression) and can be conceived of as a test of causation with respect to crowding: does density lead individuals to react aggressively or withdraw?

Equation 2 examines whether time 1 withdrawal (aggression) has an effect on time 2 density. This is the crux of the test for self-selection; the results from this equation provide an indication of whether previous levels of withdrawal or aggression lead individuals to select themselves into different housing situations characterized by particular levels of density. In other words, it is a test of reverse causation. 
The measurement model was tested using LISREL 8.14. The latent variables for both time 1 and time 2 withdrawal were estimated simultaneously since it was necessary to determine what indicators of time 2 withdrawal were correlated with the scaling indicator of time 1 withdrawal (Bollen, personal comm.). The same seven indicators were used for time 1 and time 2 withdrawal. The scaling indicator for both latent variables was the same: It is hard for me to feel close to others.

The LISREL results for the measurement model suggest that it is a good fit. $^{2}$ The root mean square error of approximation (RMSEA) has a value of 0.0089 . The value of $\mathrm{BIC}_{\mathrm{k}}$ for the current model was calculated as -214.9 . Since it is a negative value, we can conclude that $M_{\mathrm{k}}$, the current model, is preferred to the saturated model $M_{s}$. The small value of the statistic, in terms of being more negative, further emphasizes the support for $M_{\mathrm{k}}$ by the data.

The completely standardized solution indicates that the factor loadings are all well above an acceptable level, ranging from 0.55 to 0.86 for time 1 withdrawal and from 0.57 to 0.79 for time 2 withdrawal. Importantly, the model reveals that there are a number of correlated errors between the indicators within each latent variable and between the two latent variables for withdrawal. Correlated errors are a concern to the extent that they create a correlation between the instruments and the error term in the equation. Model estimation with 2SLS is not affected by a correlation between two disturbances if these disturbances are of nonscaling indicators (Bollen \& Paxton 1998). However, if there is a correlation between the disturbances of a scaling indicator and a nonscaling indicator, the variable that is correlated with the scaling indicator is not eligible to be used as an instrumental variable. Time 1 indicators of withdrawal which have a correlated error with the scaling indicator for time 2 withdrawal are also ineligible as instrumental variables (Bollen, personal comm.). The results for the current model indicate that there are correlated errors between the scaling indicator of time 1 withdrawal $\left(X_{2}\right)$ and $X_{3}, X_{5}$, and $X_{6}$, meaning that none of these indicators are eligible as instrumental variables, since this produces a correlation between these variables and the disturbance term. The scaling indicator for time 2 withdrawal $\left(\mathrm{Y}_{1}\right)$ is not correlated with any of the disturbances of the indicators of time 1 withdrawal. Therefore the indicators of time 1 withdrawal which are eligible as instrumental variables are $X_{1}, X_{4}$, and $X_{7}$.

Four objectives guided the decision-making process in selecting the instrumental variables. For each equation, instrumental variables were selected such that: (1) there were at least as many instrumental variables as there were variables in the second-stage equation; (2) the $\mathrm{R}^{2}$ for each first-stage regression was high enough to suggest that the selection of instrumental variables had not compromised the quality of the estimates (e.g. an $\mathrm{R}^{2}$ above .10); (3) the results 


\section{TABLE 2: Structural Equation Model Testing for Self-Selection and Nonlinearity in the Relationship between Density and Aggression}

Factor Loadings for Latent Variables

Aggression, Time 1

Factor
Variable $\quad$ Loading

$\mathrm{x}_{1} \quad .75$

$\mathrm{x}_{2} \quad .54$

$\mathrm{x}_{3} \quad .41$

$\mathrm{x}_{4} \quad .50$

$\mathrm{x}_{5} \quad .37$

$x_{6}$
Aggression, Time 2

Factor
Variable $\quad$ Loading

$\mathrm{y}_{1} \quad .87$

$\mathrm{y}_{2}-.51$

$\mathrm{y}_{3} \quad .40$

$\mathrm{y}_{4} \quad .49$

$\begin{array}{ll}\mathrm{y}_{5} & .38\end{array}$

$\mathrm{y}_{6} \quad .64$

Equation 1: The Effects of Time 2 Density and Density ${ }^{2}$ on Time 2 Aggression

$\begin{array}{lcc}\text { Variable } & \begin{array}{c}\text { Parameter } \\ \text { Estimate }\end{array} & \begin{array}{c}\text { Standard } \\ \text { Error }\end{array} \\ & & \\ \text { Persons per room (time 2) } & -11.659^{*} & 7.228 \\ \text { Persons per room) }^{2} \text { (time 2) } & 4.916 \dagger & 3.104 \\ \text { Aggression (time 1) } & .4398^{\star * * *} & .1129\end{array}$

Equation 2: The Effects of Time 1 Aggression on Time 2 Density

$\begin{array}{lcc}\text { Variable } & \begin{array}{c}\text { Parameter } \\ \text { Estimate }\end{array} & \begin{array}{c}\text { Standard } \\ \text { Error }\end{array} \\ & & \\ \text { Aggression (time 1) } & -.0305^{\star \star *} & .0090 \\ \text { Persons per room (time 1) } & .7532^{\star * \star *} & .0305\end{array}$

$\dagger \mathrm{p}<.10 \quad{ }^{*} \mathrm{p}<.05 \quad{ }^{\star *} \mathrm{p}<.01 \quad{ }^{\star * *} \mathrm{p}<.001 \quad{ }^{\star * * *} \mathrm{p}<.0001$

for the Basmann (1960) overidentification test supported the assumption that the instrumental variables were uncorrelated with the disturbance of the equation; and (4) only a subset of the eligible instruments were selected in light of evidence suggesting that estimates are better when only a subset of eligible instruments are used (Bollen, personal comm.).

Estimation of the structural model proceeded on the basis of Bollen's 2SLS estimation technique for modeling nonlinear relationships among latent and mixtures of latent and observed variables. The two latent variable equations of interest are written out below.

$$
L_{2}=\alpha_{L 2}+\beta_{23} L_{3}+\beta_{24} L_{3}^{2}+\beta_{21} L_{1}+\zeta_{2}
$$


FIGURE 3: Nonlinear Effect of Persons per Room on Withdrawal

Withdrawal

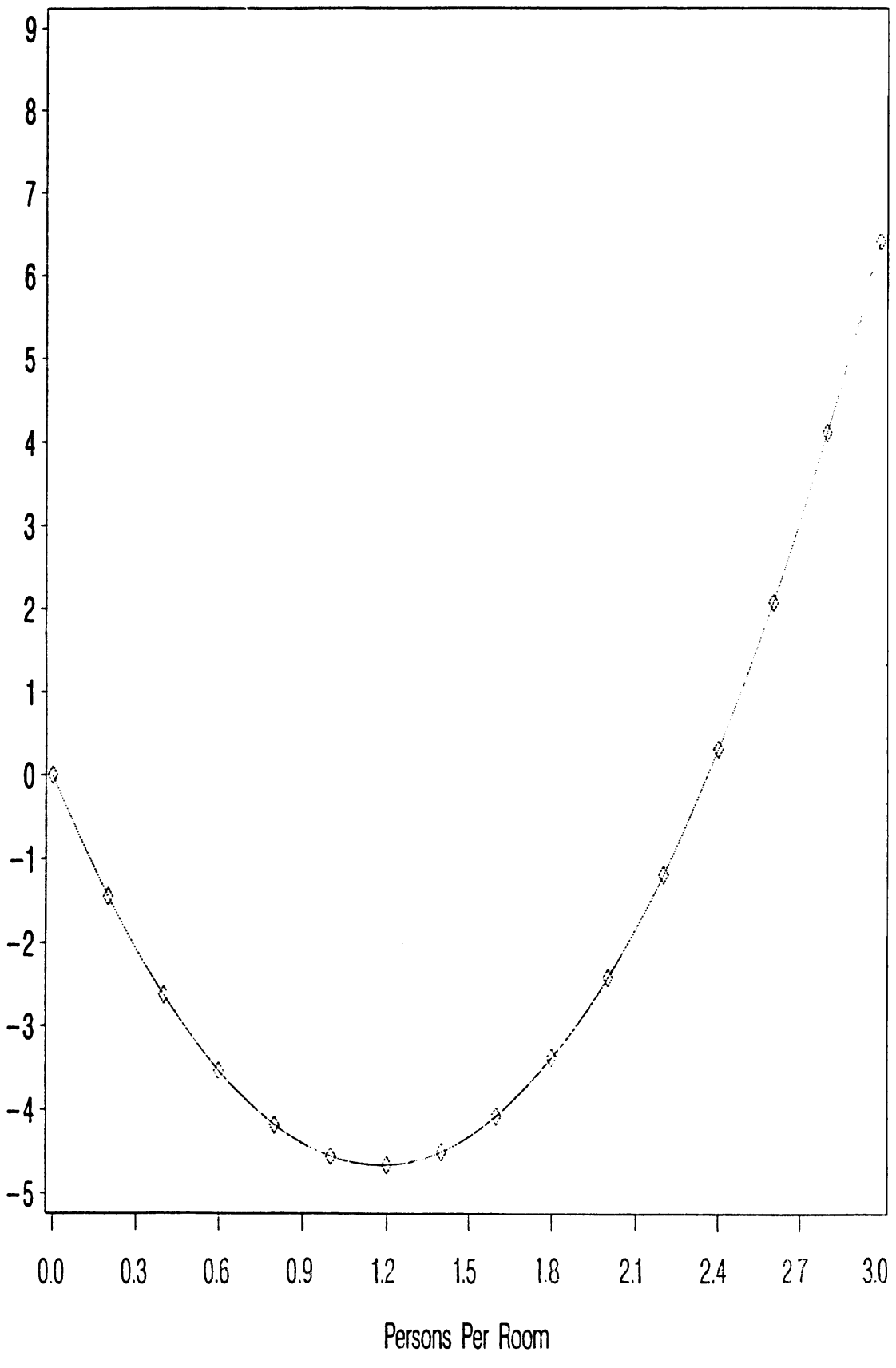




$$
L_{3}=\alpha_{L 3}+\beta_{31} L_{1}+\gamma_{38} X_{8}+\zeta_{3}
$$

Following Bollen $(1995 ; 1996)$, these equations can be rewritten as:

$$
\begin{aligned}
& Y_{1}=\alpha_{L 2}+\beta_{18} Y_{8}+\beta_{19} Y_{8}^{2}+\beta_{11} X_{1}+u_{1} \\
& Y_{8}=\alpha_{L 3}+\beta_{81} X_{1}+\gamma_{88} X_{8}+u_{8}
\end{aligned}
$$

The 2SLS results are displayed in the bottom panel of Table 1. Equation 1, which examines the immediate impact of crowding on withdrawal, suggests that there is indeed a nonlinear relationship between density and withdrawal at time 2 . The direction of the coefficients indicate that as household density increases up to a certain level, withdrawal decreases, but after that point, withdrawal begins to increase. In other words, the relationship between density and withdrawal takes the form of a j-curve, and it is only after levels of density reach a particular threshold that the effect takes off and becomes increasingly positive. We observe a decrease in negative outcomes due to early increases in levels of crowding, but the ensuing increase after that is asymmetrically positive. The threshold was calculated to be 1.18 persons per room. Up until that point, the addition of extra people in the household actually reduces levels of withdrawal. These effects remain significant with the addition of the control variables of gender, income, marital status, and ethnicity to the model (thus, these additional models are not presented).

A graph of this relationship is displayed in Figure 3. What these results reveal, then, is that there is an optimal level of household density where withdrawal will be at its lowest level. Where density is lower or higher than this, levels of withdrawal increase, although probably for different reasons. High levels of withdrawal at the lowest levels of household crowding may be a consequence of a lack of perceived social support among individuals who are living alone. In contrast, the increase in withdrawal at high crowding levels may result from the overstimulation experienced by respondents in such settings. That is, the excessive demands on attention resulting from living in a crowded home leads individuals to avoid further stimulation by shunning social interaction with others.

Equation 2, which examines whether there is an effect of time 1 withdrawal on time 2 density, is a test of reverse causation. The results do suggest there may be some self-selection of individuals who are high on withdrawal into lower-density households operating among the respondents in this sample. Time 1 withdrawal has a marginally significant impact on density at time 2 once the effects of time 1 density are partialled out, suggesting that individuals who have higher initial levels of withdrawal tend to move into less crowded households. The direction of this relationship, then, is consistent with the selfselection arguments made in the crowding literature. However, the effect does not retain its significance once control variables are added to the model. 
Various model statistics indicate that these estimates were not adversely influenced by the quality of the instrumental variables. The $\mathrm{R}^{2}$ 's for the first stage regressions of the 2SLS estimators for time 2 withdrawal, time 2 density, and time 2 density $^{2}$ are $0.25,0.35$, and 0.16 respectively. The results for the overidentification test lend further support to the argument that the selection of instrumental variables was appropriate. The Basmann test for overidentifying restrictions for the first equation produced an $F$-value of $0.44(p=0.64)$, and for the second equation the F-value was $1.97(p=0.12)$. Therefore, the choice of instrumental variables is supported by the evidence.

To assess the extent to which these results might have been influenced by the choice of scaling indicator, the models were estimated a second time using a different scaling indicator (It is hard for me to show affection to other people) but testing the same two equations. The selection of instrumental variables was made anew since it was necessary to choose a set that did not have any correlated errors with the new scaling indicator. The results for this model (not shown) reveal that both the nonlinear relationship between density and withdrawal at time 2 , as well as the effect of time 1 withdrawal on time 2 density, were replicated after changing the scaling indicator, further supporting the validity of the initial results. Moreover, the threshold for the positive effect is virtually identical to that calculated for the previous model: 1.19 persons per room.

Overall, the 2SLS results for the relationships between density and withdrawal generate more support for a causal argument in which crowding influences individuals' social behavior as opposed to a reverse causation argument where withdrawal is seen to precipitate exposure to particular levels of density. However, there is some evidence to suggest that indeed both may be occurring among the respondents in this sample.

\section{Aggression}

As with the structural equation model for withdrawal, the measurement model for aggression was tested using LISREL. Again, estimation of both time 1 and time 2 aggression occurred simultaneously in order to establish which of the indicators of aggression were correlated with the time 1 and time 2 scaling indicators. The indicators used for time 1 and time 2 aggression were equivalent, and the scaling indicator for both latent variables was the same: I am too aggressive toward other people.

The LISREL results suggest that the model is a good fit. The root mean square error of approximation (RMSEA) has a value of 0.025 . Calculating $\mathrm{BIC}_{\mathrm{k}}$ for the current model produced a value of -138.3 . Since it is a negative value, we can conclude that $M_{k}$, the current model, is preferred to the saturated model $M_{s}$. The small value of the statistic in terms of being more negative further indicates that $M_{k}$ fits the data. 
The completely standardized solution indicates that the factor loadings are at or above an acceptable level, ranging from 0.37 to 0.75 for time 1 aggression and from 0.38 to 0.87 for time 2 aggression. The results indicate that there are a number of correlated errors between the indicators within each latent variable and between the two latent variables, which has important ramifications in terms of correctly specifying the set of eligible instrumental variables. Correlated errors appear between the scaling indicator of time 1 aggression $\left(X_{1}\right)$ and $X_{2}$ and $X_{6}$, which renders these indicators ineligible. The scaling indicator for time 2 aggression $\left(Y_{1}\right)$ is also correlated with the disturbances of a number of indicators of time 1 aggression: $X_{1}, X_{2}$, and $X_{6}$. Therefore the indicators of time 1 aggression which remain eligible as instrumental variables are $X_{3}, X_{4}$, and $X_{5}$.

The latent variable equations for aggression tested using Bollen's 2SLS estimation technique are equivalent to those for withdrawal and thus need not be rewritten here. The results for equation 1 support the notion that crowding has an immediate effect on time 2 aggression. The coefficient for the nonlinear term is borderline significant, just missing the cutoff for a .05 significance level $(p=.056)$, implying some support for the hypothesized nonlinear effect (see Witte \& Witte 2001). That the squared term just fails to meet a .05 significance level may possibly be a reflection of the inefficiency of 2SLS as an estimator. These crowding effects remain even with the addition of control variables to the model. The directions of the coefficients are the same as the corresponding results for withdrawal; they indicate that aggression decreases as household density increases up to a certain level, but after that point an increasingly positive relationship between density and aggression begins to emerge. Thus, as with withdrawal, density forms a nonlinear relationship with aggression which takes the form of a $j$-curve. At the lowest levels of density, further increments in persons per room reduce levels of aggression until an optimal level of density is reached. The threshold for aggression is identical to that for withdrawal: 1.18 persons per room. After this point, the deleterious effect of density begins to take off and increased crowding leads to more aggressive responses among individuals.

The findings with respect to the test of reverse causation, equation 2, also provide support for the self-selection argument. Aggression at time 1 has a statistically significant effect on density at time 2 once the effects of time 1 density are partialled out. This effect remains significant with the addition of control variables to the model. The negative coefficient suggests that individuals experiencing higher levels of aggression at time 1 are likely to be selected into lower-density households at time 2. Intuitively, this makes sense, as highly aggressive individuals may prove to be difficult to live with and may find themselves "evicted" from the household as a result of their behavior. Alternatively, the source of their aggression - the frustration of living in a household with too many others and/or too little space - may provide them 
with the motivation and desire to relocate into more spacious (i.e., less dense) living quarters.

Various model statistics indicate that these estimates are not compromised by the quality of the instrumental variables. The $\mathrm{R}^{2}$ 's for the first stage regressions for $X_{1}, Y_{7}$, and $Y_{8}$ were $0.24,0.36$, and 0.16 respectively. Thus, the choice of instrumental variables is supported by the available evidence.

As with withdrawal, the aggression models were estimated a second time using a different scaling indicator in order to examine the sensitivity of the results to the particular scaling indicator selected. In this case the chosen indicator was: I manipulate other people too much to get what I want. The results of this analysis (not shown) show that changing the scaling indicator does not have a noticeable impact on the results. There is still evidence of both causation and selection going on, and the relationship between density and aggression remains nonlinear in nature. The threshold for a positive effect based on this model was calculated to be 1.19 persons per room. That the earlier findings for aggression were replicated with the use of a different scaling indicator provides further support for the validity of the initial results.

Overall, the 2SLS results for the relationship between density and withdrawal and between density and aggression lend themselves to a both a causal and self-selection interpretation of the effects of crowding on human social behavior. Importantly, the current findings do generate some support for those arguments in which density is viewed as a consequence, rather than a cause, of these behavioral outcomes, although this appears to be more the case for aggression than for withdrawal.

The models were reestimated using the full-information method of LISREL as a comparison for the 2SLS results, since LISREL has been demonstrated to be a more efficient technique than two-stage least squares. The same scaling indicators were selected as those which were used in the 2SLS models. Time 1 density and withdrawal (aggression) were modeled as exogenous latent variables. Time 2 density, density ${ }^{2}$, and withdrawal (aggression) were modeled as endogenous latent variables. Density and density ${ }^{2}$, regardless of time point, were given a scaling indicator of 1 , thus treating them as perfectly measured variables. This constraint was necessary in order for the model to be identified. The model allowed for effects of time 1 density on time 2 density, and time 1 withdrawal (aggression) on time 2 withdrawal (aggression), in addition to including the relationships of interest to be tested. As before, the models allowed for correlated errors among various indicators of time 1 withdrawal (aggression) and among several indicators of time 2 withdrawal (aggression). The modification indices pointed to the need to allow for some correlated errors across the two different measures of withdrawal and aggression, and these too were incorporated.

The results for the model for withdrawal (not shown) indicate that the factor loadings for both measures of withdrawal are above an acceptable level, 
ranging from 0.51 to 0.86 for time 1 withdrawal and 0.57 to 0.93 for time 2 withdrawal. The findings with respect to the effects of time 2 density and time 2 density $^{2}$ on time 2 withdrawal reveal that while the effect of density on withdrawal is significant $(p<.05)$, the coefficient for density squared is not. The direction of the coefficients do match those of the 2SLS results, with the linear term being negative and the quadratic term positive. Time 1 withdrawal also showed a significant negative effect on time 2 density $(p<.001)$. For the aggression model, the factor loadings, although slightly lower than the corresponding model for withdrawal, were at or above an acceptable level, ranging from 0.36 to 0.72 for time 1 aggression and 0.33 to 0.78 for time 2 aggression. ${ }^{3}$ The pattern of findings is very similar to what occurred in the model for withdrawal. Density showed a marginally significant effect on time 2 aggression $(p<.10)$, but the density ${ }^{2}$ coefficient did not achieve significance. Again the coefficients follow the pattern of a negative linear term and a positive nonlinear term. Time 1 aggression has a significant effect on time 2 density $(p<.001)$.

In spite of the fact that two quite different estimation techniques were used to test causation and selection hypotheses concerning the effects of density and withdrawal and of density and aggression, the findings from the LISREL and 2SLS models show a great deal of consistency. Both sets of results revealed a significant negative effect of time 1 withdrawal/aggression on time 2 density. They also each showed a significant negative effect of density on both withdrawal and aggression. Where they differed was with respect to whether the effects of time 2 density on withdrawal or aggression were nonlinear. The 2SLS results reveal a nonlinear relationship between density and withdrawal and, to a lesser extent, aggression. This relationship takes the form of a $j$-curve, in which the lowest levels of density lead to a reduction in withdrawal or aggression up to a point, after which the effect becomes increasingly positive. The quadratic term in the LISREL model, however, did not achieve significance (although its direction was consistent with the form of the nonlinear relationship in the 2SLS models). However, the discrepancy between the two sets of results regarding the issue of the significance of the quadratic term may have to do with the very reason for selecting 2SLS in the first place as the primary means for testing self-selection arguments. That issue concerns the possibility that the variables used in the analysis came from a nonnormal distribution, which is of particular relevance given the use of a quadratic term. Since Bollen's 2SLS estimator does not rely on an assumption of normality, the findings using his estimator lend themselves to greater confidence. More importantly, one of the very advantages of a technique such as LISREL lies in the fact that it is a more efficient estimator, and therefore one is inclined to find more significant results. However, with respect to the current findings, the more significant results appeared in the two-stage least squares models. 


\section{Discussion and Implications}

Common sense has long suggested that as more and more people try to share a limited amount of space, undesirable consequences will result. Attempts to empirically demonstrate such a relationship, however, have provided less than overwhelming support for the idea. However, as sociologists know all too well, the real world seldom operates in such a simplistic way. This need not be viewed as a deterrent to researching these kinds of processes. Rather, it requires students of population density to be extremely careful in how they go about specifying the effects of high density on human behavior. Instead of approaching the issue of density as a question of what its impact will be, a much more fruitful course of action is to ask when, and under what conditions, will high density influence human social behavior (Walker \& Cohen 1985).

This second approach forms the basis of the current research. The major premise of this article has been that, in spite of the volumes of research on the topic, the effects of density in the current literature have been fundamentally misspecified. The consequences of this misspecification have been twofold. First, the density literature is fraught with inconsistent findings. Second, after decades of investing a great deal of time, energy, and resources into understanding the problems of population density, we are still a considerable distance away from any kind of definitive answer on the issue. One of the major goals of the current research has been to begin making some significant strides towards this objective. To this end, this study proposed a respecification which addressed two major problems in the existing approaches to research on the effects of density.

The first of these addressed the issue of self-selection. Although many of the findings in the current research may actually reflect a self-selection of individuals into particular types of housing, this kind of alternative explanation has largely been ignored and virtually never empirically examined. The present study makes a substantial contribution to the existing literature by explicitly testing causation and selection explanations for the effects of density on human behavior. Drawing on the panel nature of the data, structural equation modeling tested for the effects of earlier levels of density on later levels of aggression and withdrawal, as well as earlier social behavior on later levels of density. The analysis used two of the more sophisticated techniques available for examining structural equation models containing nonlinear relationships: Bollen's two-stage least squares estimator $(1995,1996)$, and LISREL. Importantly, the findings pointed to the operation of both selection and causation in terms of the relationship between density and behavior. In other words, it is not only the case that individuals may exhibit aggression and/or withdrawal as a response to high-density conditions, but individuals with tendencies toward aggressive and/or withdrawn behavior also select themselves into lower-density housing environments. Thus, the results of the current 
research bring into doubt many of the conclusions reported in the existing research, which overwhelming have failed to address and examine self-selection as a possible explanation for their findings.

A second glaring shortcoming in the existing density literature concerns the possibility that the effects of density on various outcomes are nonlinear in nature. That there may be an optimal level of density, above or below which human social behavior is negatively impacted, is a fundamental consideration in correctly specifying the effects of density. In particular, if the relationship is modeled as linear when in fact it is nonlinear, the significance of the effects of density are likely to be understated or missed entirely. Even if they are not, they will be fundamentally misspecified. One of the key findings of the current research is its support for the suggestion that the relationship of density to various behavioral outcomes is indeed nonlinear. In particular, the pattern observed here indicates that the likelihood of withdrawal and, to a lesser extent, aggression decreases at very low levels of persons per room, but once a threshold is met, exponential increases in withdrawn or aggressive behavior occur. Thus, the relationship between density and behavior takes the form of a j-curve. Controlling for other factors such as income, gender, marital status, and ethnicity did not alter this relationship.

The problems caused by the structure of particular living environments cannot be adequately addressed without an understanding of how individuals are affected by both very low and very high levels of density. More generally speaking, it is likely that many aspects of the social world are related in a way similar to the $j$-curve found here. That is, a number of the relationships of interest to social scientists are probably subject to threshold effects, where the impact or influence of a particular variable is only evident once it reaches a specific level. The reliance of sociologists on largely linear models suggests that many of these kinds of relationships have been missed entirely.

\section{Notes}

1. The validity of persons per room as a measure of crowding has been the subject of some debate in the literature. Its use is based on the assumption that holding the number of persons constant while reducing the number of rooms will lead to a reduction in ability to regulate interaction, in turn decreasing privacy and generating an experience of crowding (Gove et al. 1979). Booth and Edwards (1976:81) caution against the operationalization of density as persons per room, asserting that "this estimate of crowding may not reflect the actual amount of contact between household members or the extent to which they might interfere with each other's activities." However, Gove and his colleagues $(1979 ; 1983)$ have validated its use to the extent that they have demonstrated that persons per room is strongly related to both lack of privacy and felt demands.

2. Due to the size of the sample used here and the sensitivity of chi-square to sample size (Jöreskog 1969), two alternative fit measures were selected for judging model fit: 
the root mean square error of approximation and the Bayesian Information Criterion (BIC) (Rafterty 1995).

3. The factor loadings for one particular indicator of aggression in both waves of the data, the scale item "I like people to be afraid of me," were consistently lower than the others in both the LISREL models and in the measurement models tested previously in the 2SLS analysis. In order to ensure that the results had not been adversely affected by the presence of an indicator with a lower factor loading than the rest, the LISREL model was rerun a second time, dropping this indicator from each of the latent variables. The results for the model dropping this indicator did not show any substantial changes in the factor loadings for the remaining indicators, and the same conclusions emerged with respect to the effects of time 2 density and density squared on aggression, as well as the effects of time 1 aggression on time 2 density. Thus, these findings suggest that in spite of having a lower factor loading than the other indicators, the inclusion of this scale item has not had an adverse impact on the results.

\section{References}

Aiello, John R., Gregory Nicosia, and Donna E. Thompson. 1979. "Physiological, Social, and Behavioral Consequences of Crowding on Children and Adolescents." Child Development 50:195-202.

Aiello, John R., Donna E. Thompson, and Andrew Baum. 1984. "Children, Crowding, and Control: Effects of Environmental Stress on Social Behavior." Pp. 97-124 in Habitats for Children: The Impacts of Density, edited by Joachim F. Wohlwill and W. van Vliet. Erlbaum.

Allee, W.C. 1938. The Social Life of Animals. Boston: Beacon Press.

Allee, W.C., Orlando Park, Alfred E. Emerson, Thomas Park, and Karl P. Schmidt. 1949. Principles of Animal Ecology. W.B. Saunders.

Altman, Irwin. 1975. The Environment and Social Behavior. Brooks/Cole.

Baldassare, Mark. 1979. Residential Crowding in Urban America. University of California Press.

Baron, Reuben M., and Judith Rodin. 1978. "Personal Control and Crowding Stress: Processes Mediating the Impact of Spatial and Social Density." Pp. 145-90 in Advances in Environmental Psychology, vol. 1, edited by Andrew Baum, Jerome M. Singer, and Stuart Valins. Erlbaum.

Basmann, R.L. 1960. "On Finite Sample Distributions of Generalized Classical Linear Identifiability Test Statistics.” Econometrica 45:939-52.

Baum, Andrew, and Stuart Koman. 1976. "Differential Response to Anticipated Crowding: Psychological Effects of Social and Spatial Density." Journal of Personality and Social Psychology 34:526-36.

Baum, Andrew, and Paul B. Paulus. 1991. "Crowding." Pp. 533-70 in Handbook of Environmental Psychology, vol. 1, edited by Daniel Stokols and Irwin Altman. Krieger.

Baum, Andrew, and Stuart Valins. 1979. "Architectural Mediation of Residential Density and Control: Crowding and the Regulation of Social Contact." Pp. 131-75 in Advances in Experimental Social Psychology, vol. 12, edited by Leonard Berkowitz. Academic Press.

Beasley, Ronald W., and George Antunes. 1974. "The Etiology of Urban Crime: An Ecological Analysis." Criminology 11:439-61. 
Bollen, Kenneth A. 1995. "Structural Equation Models that are Nonlinear in Latent Variables: A Least Squares Estimator." Pp. 223-51 in Sociological Methodology, 1995, edited by Peter V. Marsden. Blackwell.

Bollen, Kenneth A. 1996. "An Alternative Two Stage Least Squares (2SLS) Estimator for Latent Variable Equations.” Psychometrika 61:109-21.

Bollen, Kenneth A., and Pamela Paxton. 1998. "Two-Stage Least Squares Estimation of Interaction Effects." Pp. 125-51 in Interaction and Nonlinear Effects in Structural Equation Modeling, edited by Randall E. Schumacker and George A. Marcoulides. Lawrence Erlbaum.

Booth, Alan. 1976. Urban Crowding and Its Consequences. Praeger.

Booth, Alan, and John Cowell. 1976. "Crowding and Family Relations." Journal of Health and Social Behavior 17:204-20.

Booth, Alan, and John N. Edwards. 1976. "Crowding and Health." American Sociological Review 41:308-32.

Booth, Alan, Susan Welch, and David R. Johnson. 1976. "Crowding and Urban Crime Rates." Urban Affairs Quarterly 11:291-307.

Calhoun, John B. 1962. "Population Density and Social Pathology." Scientific American 206: 13948.

Carnahan, Douglas, Walter Gove, and Omer R. Galle. 1974. "Urbanization, Population Density, and Overcrowding: Trends in the Quality of Life in Urban America." Social Forces 53:6272.

Christian, J.J. 1961. "Phenomena Associated with Population Density." Proceedings of the National Academy of Science 47:428-49.

1963. "Endocrine Adaptive Mechanisms and the Physiologic Regulation of Population Growth." Pp. 189-353 in Physiological Mammalogy, vol. 1., edited by William Mayer and Rchard G. Van Gelder. Academic Press.

_. 1970. "Social Subordination, Population Density, and Mammalian Evolution." Science 168:84-94.

Christian, J.J., V. Flyger, and David E. Davis. 1960. "Factors in the Mass Mortality of a Herd of Sika Deer Cervus nippon." Chesapeake Science 1:79-95.

Clulow, F.V., and J. R. Clarke. 1968. "Pregnancy-block in Microtus agrestis and Induced Ovulator." Nature 219:511.

Davis, David E. 1964. “The Physiological Analysis of Aggressive Behavior." Pp. 53-74 in Social Behavior and Organization among Vertebrates, edited by William Etkin. University of Chicago Press.

1971. "Physiological Effects of Continued Crowding." Pp. 133-47 in Behavior and Environment, edited by Aristide H. Esser. Plenum.

Eibl-Eibesfeldt, Irenäus. 1970. Ethology: The Biology of Behavior. Holt, Rinehart, and Winston.

Evans, Gary W., Eunju Rhee, Camille Forbes, Karen Mata Allen, and Stephen J. Lepore. 2000. "The Meaning and Efficacy of Social Withdrawal as a Strategy for Coping with Chronic Residential Crowding." Journal of Environmental Psychology 20:335-42.

Factor, Robert, and Ingrid Waldron. 1973. "Contemporary Population Densities and Human Health." Nature 243:381-84.

Flickinger, G. L. 1966. "Response of the Testes to Social Interaction among Grouped Chickens." General Comparative Endocrinology 6:89-98. 
Freedman, Jonathan L. 1975. Crowding and Behavior. Freeman.

Gabe, Jonathan, and Paul Williams. 1986. "Is Space Bad for Your Health? The Relationship Between Crowding in the Home and Emotional Distress in Women." Sociology of Health and Illness 8:351-71.

Galle, Omer R., and Walter R. Gove. 1978. "Overcrowding, Isolation, and Human Behavior: Exploring the Extremes in Population Distribution." Pp. 95-132 in Social Demography, edited by Karl E. Taeuber, Larry L. Bumpass, and James A. Sweet. Academic Press.

Galle, Omer R., Walter R. Gove, and J. Miller McPherson. 1972. "Population Density and Pathology: What Are the Relations for Man?" Science 176:23-30.

Gillis, A.R. 1974. "Population Density and Social Pathology: The Case of Building Type, Social Allowance and Juvenile Delinquency." Social Forces 53:306-14.

1979. "Household Density and Human Crowding: Unravelling a Non-Linear Relationship." Journal of Population 2:104-17.

Gillis, A. R., and John Hagan. 1983. "Bystander Apathy and the Territorial Imperative." Sociological Inquiry 53:449-60.

Gove, Walter R,. and Michael Hughes. 1983. Overcrowding in the Household: An Analysis of Determinants and Effects. Academic Press.

Gove, Walter R., Michael Hughes, and Omer R. Galle. 1979. "Overcrowding in the Home: An Empirical Investigation of its Possible Pathological Consequences." American Sociological Review 44:59-80.

$\rightarrow$ Greenberg, Gary. 1972. "The Effects of Ambient Temperature and Population Density on Aggression in Two Inbred Strains of Mice, Mus musculus." Behaviour 42:119-30.

Gregor, Gary L., Richard F. Smith, Lynn S. Simons, and Howard B. Parker. 1972. "Behavioral Consequences of Crowding in the Deermouse (Permyscus maniculatus)." Journal of Comparative and Physiological Psychology 79:488-93.

Hawley, Amos H. 1972. "Population Density and the City." Demography 9:521-29.

Hoffman, R.S. 1958. "The Role of Reproduction and Mortality in Population Fluctuations of Wolves (Microtus)." Ecological Monographs 28:79-109.

Hughes, Michael, and Walter R. Gove. 1981. "Living Alone, Social Integration, and Mental Health." American Journal of Sociology 87:48-74.

Hutt, Corinne, and M. Jane Vaizey. 1966. "Differential Effects of Group Density on Social Behavior." Nature 209:1371-72.

Jacobs, Jane. 1961. The Death and Life of Great American Cities. Vantage.

Jain, Uday. 1987. The Psychological Consequences of Crowding. Sage.

Johnston, John. 1984. Econometric Methods. McGraw-Hill.

Jöreskog, Karl. G. 1969. "A General Approach to Confirmatory Maximum Likelihood Factor Analysis.” Psychometrika 34:183-202.

Jöreskog, Karl G., and Dag Sörbom. 1995. LISREL 8.14. Scientific Software.

Keane, Carl R. 1989. "Loose Coupling in Tight Places: Gender and Psychological Strain Among Public Housing Residents." Doctoral dissertation, University of Toronto.

Keeley, K. 1962. "Prenatal Influence on Behavior of Offspring of Crowded Mice. Science 135: 44 45. 
Lawrence, John E.S. 1974. "Science and Sentiment: Overview of Research on Crowding and Human Behavior." Psychological Bulletin 81:712-20.

Lepore, Stephen J., Gary W. Evans, and M.N. Palsane. 1991. "Social Hassles and Psychological Health in the Context of Chronic Crowding." Journal of Health and Social Behavior 32: 35767.

Lepore, Stephen J., Gary W. Evans, and Margaret L. Schneider. 1991. "Dynamic Role of Social Support in the Link Between Chronic Stress and Psychological Distress." Journal of Personality and Social Psychology 61:899-909.

Lockley, R.M. 1961. "Social Structure and Stress in the Rabbit Warren." Journal of Animal Ecology 30:385-423.

Loo, Chalsa M. 1972. "The Effects of Spatial Density on the Social Behavior of Children." Journal of Applied Social Psychology 4:372-81.

1978. "Density, Crowding, and Preschool Children." Pp. 371-86 in Human Response to Crowding, edited by Andrew Baum and Yakov Epstein. Erlbaum.

1979. "A Factor Analytic Approach to the Study of Spatial Density Effects on Preschoolers." Journal of Population 2:47-68.

Lorenz, Konrad. 1967. On Aggression. Methuen.

Mackintosh, Elizabeth, Sheree West, and Susan Saegert. 1975. “Two Studies of Crowding in Urban Public Spaces." Environment and Behavior 7:159-84.

McBride, Glen. 1971. "Theories of Animal Spacing: The Role of Flight, Fight and Social Distance." Pp. 53-68 in Behavior and Environment, edited by Aristide H. Esser. Plenum.

Michelson, William. 1976. Man and His Urban Environment: A Sociological Approach. 2d ed. Addison-Wesley.

Michelson, William, and Kevin Garland. 1974. "The Differential Role of Crowded Homes and Dense Residential Areas in the Incidence of Selected Symptoms of Human Pathology." Research Paper No. 67. Centre for Urban and Community Studies, University of Toronto.

Milgram, Stanley. 1970. “The Experience of Living in Cities.” Science 167:1461-68.

Morris, Desmond. 1967. The Naked Ape. Bantam.

1971. The Human Zoo. Bantam.

Myers, K., L.S. Hale, R. Mykylowycz, and R.L. Hughes. 1971. “The Effects of Varying Density and Space on Sociality and Health in Animals." Pp. 148-87 in Behavior and Environment, edited by Aristide H. Esser. Plenum.

Petrusewicz, K. 1957. “Investigation of Experimentally Induced Population Growth." Ekologija Polska 5:281-309.

Proshansky, Harold M., William H. Ittelson, and Leanne G. Rivlin. 1970. "Freedom of Choice and Behavior in a Physical Setting." Pp. 173-83 in Environmental Psychology, edited by Harold Proshansky, William Ittelson, and Leanne Rivlin. Holt.

Raftery, Adrian E. 1995. "Bayesian Model Selection in Social Research.” Pp. 111-63 in Sociological Methodology, edited by Peter V. Marsden. Blackwell.

Rapoport, A. 1975. “Toward a Redefinition of Density." Environment and Behavior 7:133-58.

Simmel, Georg. [1905] 1957. “The Metropolis and Mental Life.” Pp. 635-46 in Cities and Society, edited by Paul K. Hatt and Albert J. Reiss Jr. Free Press. 
Stokols, Daniel, Marilyn Rall, Berna Pinner, and John Schopler. 1973. "Physical, Social, and Personal Determinants of the Perception of Crowding." Environment and Behavior 5:87115.

Sundstrom, Eric. 1975. “An Experimental Study of Crowding: Effects of Room Size, Intrusion, and Goal-Blocking on Nonverbal Behaviors, Self-Disclosure, and Self-Reported Stress. Journal of Personality and Social Psychology 32:645-54.

Sundstrom, Eric. 1978. "Crowding as a Sequential Process: Review of Research on the Effects of Population Density on Humans." Pp. 32-71 in Human Response to Crowding, edited by A. Baum and Y.M. Epstein. Erlbaum.

Terman, C. R. 1965. "A Study of Population Growth and Control Exhibited in the Laboratory by Prairie Deermice.” Ecology 46:890-95.

Thiessen, D.D., and David A. Rodgers. 1961. "Population Density and Endocrine Function." Psychological Bulletin 58:441-51.

Turner, R. Jay, and Blair Wheaton. 1992. "Psychiatric Distress and the Use and Abuse of Alcohol and Drugs." Social Sciences and Humanities Research Council of Canada.

Valins, Stuart, and Andrew Baum. 1973. "Residential Group Size, Social Interaction, and Crowding." Environment and Behavior 5:421-39.

van den Berghe, Pierre L. 1974. "Bringing Beasts Back In: Toward a Biosocial Theory of Aggression." American Sociological Review 39:777-88.

van Vliet, Willem. 1985. "The Role of Housing Type, Household Density, and Neighborhood Density in Peer Interaction and Social Adjustment." Pp. 165-200 in Habitats for Children: The Impacts of Density, edited by Joachim F. Wohlwill and Willem van Vliet. Lawrence Erlbaum.

Verbrugge, Lois M., and Ralph B. Taylor. 1980. “Consequences of Population Density and Size.” Urban Affairs Quarterly 16:135-60.

Walker, Henry A., and Bernard P. Cohen. 1985. "Scope Statements: Imperatives for Evaluating Theory." American Sociological Review 50:288-301.

Willis, F.N. 1966. "Fighting in Pigeons Relative to Available Space." Psychonometric Science 4: $315-16$.

Wirth, Louis. 1938. “Urbanism as a Way of Life.” American Journal of Sociology 44:1-24.

Witte, Robert S., and John S. Witte. 2001. Statistics. 6th ed. Harcourt.

Wolfgang, Marvin E. 1970. "Urban Crime." Pp. 245-81 in The Metropolitan Enigma, edited by James Q. Wilson. Doubleday Anchor.

Worchel, Stephen, and Charles Teddlie. 1976. "The Experience of Crowding: A Two-Factor Theory." Journal of Personality and Social Psychology 34:30-40. 